\title{
Study on the high-precision shrink-fit holders for micro/nano milling
}

\author{
X. Cheng ${ }^{1, a *}$, J.C. Liü ${ }^{2, b}$, G.M. Zheng ${ }^{1, c}$
}

1: School of Mechanical Engineering, Shandong University of Technology, Zibo, 255049, China

2: School of Engineering and Computer Science, University of the Pacific, Stockton,95211, USA

aemail: happychengx@163.com, bemail: jliu@pacific.edu, ${ }^{\mathrm{c} e m a i l:}$ zhengguangming@ sdut.edu.cn

Keywords: Shrink-fit clamping, Finite element method, Tool holder, Micro/nano milling

\begin{abstract}
In micro/nano milling, the accuracy of tools in high-speed motion and the correspondingly final milled precision are greatly affected by the holder. Shrink-fit tool holders have high precision in principle to assure micro/nano milling since there is no medium between the holder and the cutter. Aiming at micro/nano milling, this study provides a systematic modeling and analysis process for shrink-fit holders. The heating and cooling rules of the shrink-fit holder are analyzed for various cases to study the deformation and stress fields. It shows that the clamping hole size is the critical factor affecting the insert of the tool and the material failure possibilities. The outside size of the tool holder has limited effect on the heating and cooling processes. The clamping torque is large enough for even heavy-duty micro/nano milling applications. Based on the models and analytical results, a systematic design procedure for novel shrink-fit tool holders is proposed.
\end{abstract}

\section{Introduction}

One of the most important error sources affecting the tool change accuracy, the radial runout, and the axial float is the error introduced by the tool holder. Especially in high-speed or micro/nano milling processes, the error introduced by the tool holder is the key factor for success. In such applications, the tool changing and clamping accuracies are expected to be in the range of 2 to $3 \mu \mathrm{m}$ or even smaller. Furthermore, large-scale, deep cavity and complicated freeform features in die/moulds, turbines etc need lengthened tool holders without screw nuts or other additional clamping components which will affect the machining capability, the stiffness, the balance accuracy, and the clamping strength. The shrink-fit tool holders with simple structures are more suitable for these requirements $[1,2]$. It has been experimentally evaluated that the shrink-fit tool holders have better performances than that of conventional collet chucks or static pressure expansive chucks [3].

Shrink-fit assembly is used to keep relatively fixed and in most cases to transmit torque between two components by the radial high pressures at the interface of them. It is widely used in various industrial fields such as tool holders, turbine wheels, gear trains, etc. Shrink-fit assembly is affected by many factors including the interference between the jointed two parts, the geometric accuracy, the surface finish, the working stresses, etc $[4,5]$. The dynamic characteristics including natural frequency and mode shape of the conjunction model are analyzed and recommendations of the reasonable rotational speed are given for the specific shrink-fit holder [1]. The stiffness and damping behaviors between the tool and the holder in thermal shrink-fit connections have been modeled and studied [6]. An interference fit in ring gear-wheel connections has been designed using a tolerancing method based on the finite element method (FEM) [7]. Two different methods are used to analyze the shrink fit with assumptions of no friction and a know contact domain [8]. A torque is applied to the shaft in a shrink-fit assembly giving a region of slip between the shaft and the socket. This approach has been applied to study the shrink-fitted shafts in wheels [9]. The stresses and deformations in the shrink-fitted hub-shaft joint for various forms have been analyzed [10]. 
According to the above mentioned literatures, there are discrete studies for shrink-fit assemblies. The systematic modeling and analysis process to facilitate the novel design and development of shrink-fit tool holders is required. Based on the FEM models and analytical results in deformations, stress fields considering key design factors of the tool holders, a systematic design procedure for novel shrink-fit tool holders is proposed. Small and large-sized shrink-fit tool holder prototypes are developed based on the study and experimentally evaluated.

\section{FEM analysis}

The FEM model of the shrink-fit tool holder is created in Abaqus CAE and conducted in Abaqus 6.11. The material of the tool holder is the SUS stainless steel with the density of $7850 \mathrm{Kg} / \mathrm{m}^{3}$, the Young's modulus of $206 \mathrm{GPa}$, the Poisson's ratio of 0.3 , the specific heat of $437 \mathrm{~J} /\left(\mathrm{Kg} \cdot{ }^{\circ} \mathrm{C}\right)$, the conductivity of $15.2,17.3,19.2,20.7$ at $20^{\circ} \mathrm{C}, 200{ }^{\circ} \mathrm{C}, 400{ }^{\circ} \mathrm{C}, 500{ }^{\circ} \mathrm{C}$ respectively, the expansion coefficient alpha of $1.67 \mathrm{E}-5,1.72 \mathrm{E}-5,1.75 \mathrm{E}-5,1.77 \mathrm{E}-5$ at $100{ }^{\circ} \mathrm{C}, 200{ }^{\circ} \mathrm{C}, 400{ }^{\circ} \mathrm{C}, 500{ }^{\circ} \mathrm{C}$ respectively. The geometric dimensions and the FEM meshed model of the shrink-fit tool holder are shown in Fig. 1. The end surface A is fixed in simulations.
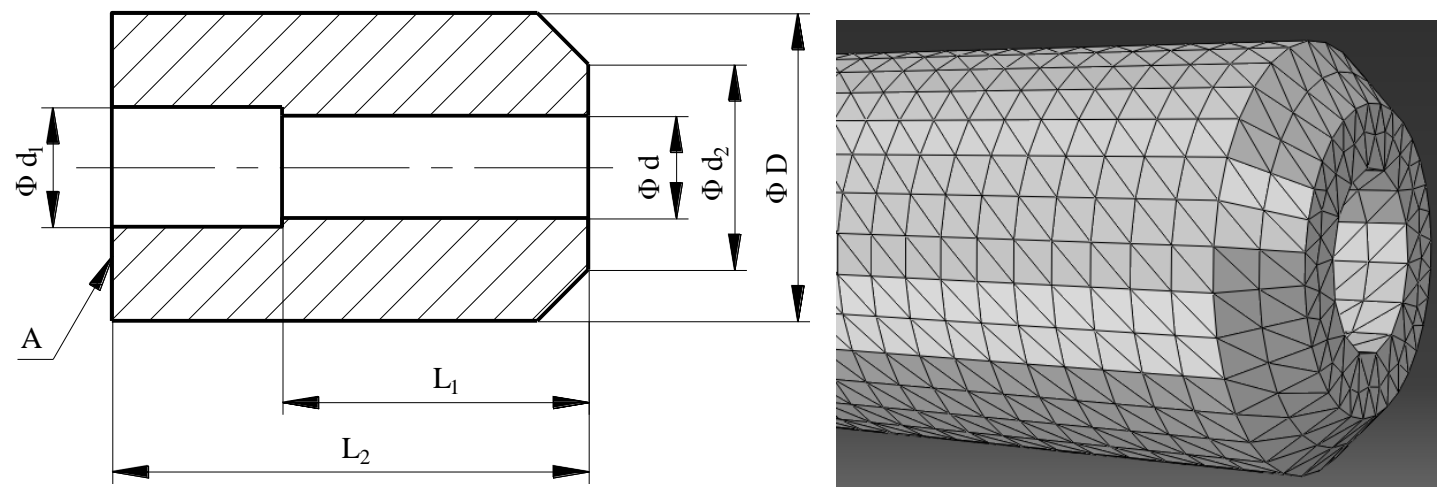

Fig. 1 The schematic model of the shrink-fit tool holder

The heating FEM model is used to identify the expansions of the key dimensions of the tool holder. Then the hole size can be estimated whether the tool can be smoothly inserted. The key dimensions after heating will be used for FEM modeling of the cooling processes. In the cooling process, the stresses and the contact pressures will be calculated for analysis. Therefore, it is necessary to verify the FEM models by comparing the simulation results from the heating and cooling models firstly. The dimensions of the shrink-fit tool holder (case 1) are given in Table 1 based on experiences, which is used for micro/nano milling tools with the shank diameter of $3 \mathrm{~mm}$.

Table 1 Geometric dimensions of case 1

\begin{tabular}{|c|c|c|c|c|c|}
\hline $\mathrm{d}(\mathrm{mm})$ & $\mathrm{D}(\mathrm{mm})$ & $\mathrm{L}_{1}(\mathrm{~mm})$ & $\mathrm{L}_{2}(\mathrm{~mm})$ & $\mathrm{d}_{1}(\mathrm{~mm})$ & $\mathrm{d}_{2}(\mathrm{~mm})$ \\
\hline 2.990 & 7.0 & 9.0 & 14.0 & 3.5 & 5.0 \\
\hline
\end{tabular}

The temperature loads versus the simulation time are that, from the time $1 \mathrm{~s}$ to $1.5 \mathrm{~s}$, temperature increases from $20^{\circ} \mathrm{C}$ to $450{ }^{\circ} \mathrm{C}$ and the model is held at $450{ }^{\circ} \mathrm{C}$ to let the model stable.

The cooling process is to be modeled independently based on the heating deformation results. In the cooling process, the tool-holder assembly is modeled. The new geometric model of the tool holder after heating is created by given the new dimensions of the device, which is derived from heating FEM simulations, as the $\mathrm{d}=3.0119 \mathrm{~mm}, \mathrm{~d}_{2}=5.0364 \mathrm{~mm}, \mathrm{D}=7.0510 \mathrm{~mm}$, and $\mathrm{L}_{2}=14.0889 \mathrm{~mm}$. The simulation results are shown in Fig. 2 (a) and (b). The expansions and the shrinkage of the three key dimensions of the tool holding device are shown in Fig. 2 (c) and (d), respectively. The final steady values are summarized in Table 2 . 
Table 2 Expansions and shrinkage of case 1

\begin{tabular}{|l|c|c|c|}
\hline & $\mathrm{d}(\mu \mathrm{m})$ & $\mathrm{d}_{2}(\mu \mathrm{m})$ & $\mathrm{D}(\mu \mathrm{m})$ \\
\hline Heating expansion & 10.942 & 18.179 & 25.501 \\
\hline Cooling shrinkage & 11.136 & 18.551 & 25.858 \\
\hline
\end{tabular}

From Fig. 2 (c), (d) and Table 2, it can be noticed that the deformation differences between the independent heating model and the cooling model are within sub-micron level, which is commensurate with the geometric accuracy in the holder and tool fabrications used for micro/nano milling. Therefore, the FEM modeling methods in this paper are verified successfully.

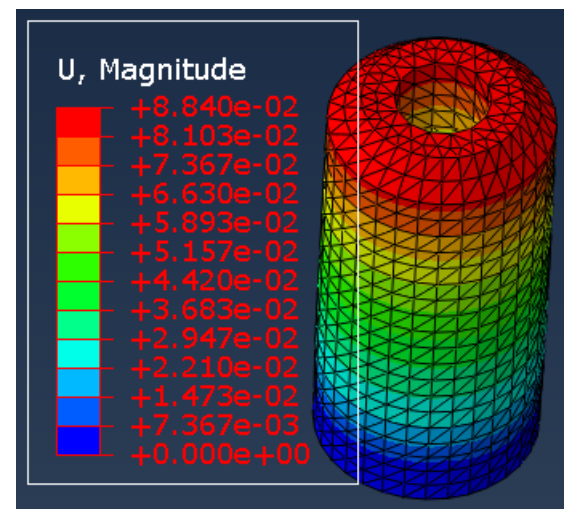

(a) Heating expansion

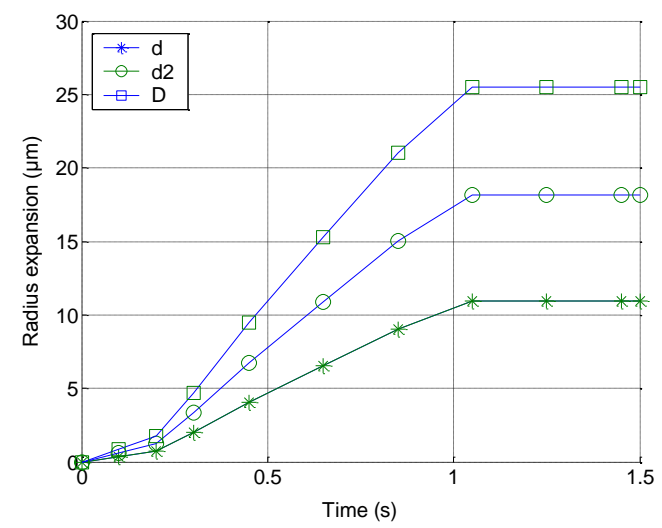

(c) Heating expansion

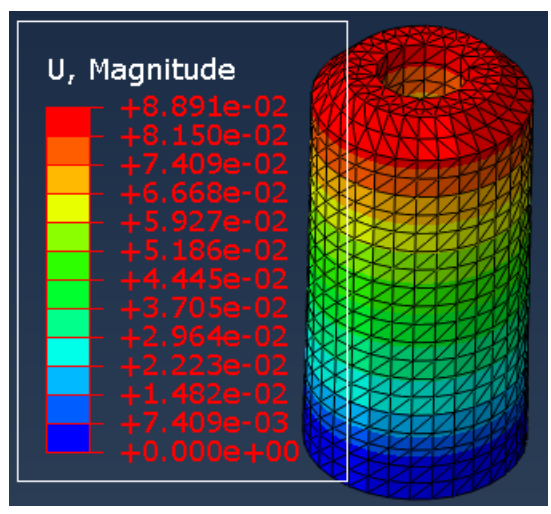

(b) Cooling shrinkage

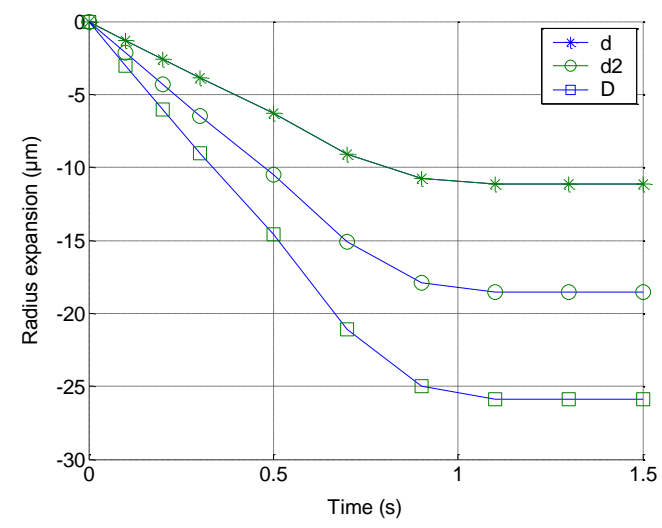

(d) Cooling shrinkage

Fig. 2 Heating and cooling simulations

During the cooling process, the clamping stress between the tool holder and the tool should be smaller than the material yielding stress and the clamping torque should be larger enough than the torque generated in the material removal process in micro/nano milling processes.

The simulation results are shown in Fig. 3. In Fig. 3(a), the maximum Mises stress is $1327 \mathrm{MPa}$. The maximum Mises stress on the clamping surface is $654.222 \mathrm{MPa}$, which is lower than the material yielding stress $(1110 \mathrm{MPa})$ of the tool holder. It means no material failure will happen for case 1 . 


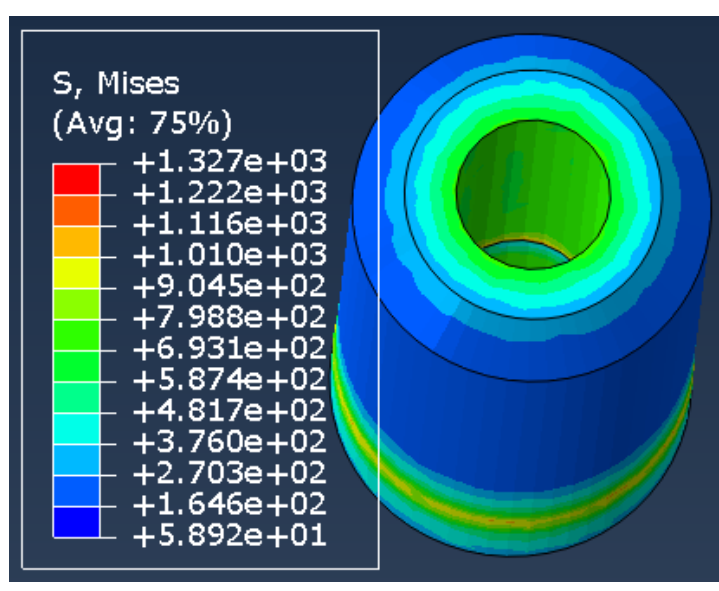

(a) Stress distribution

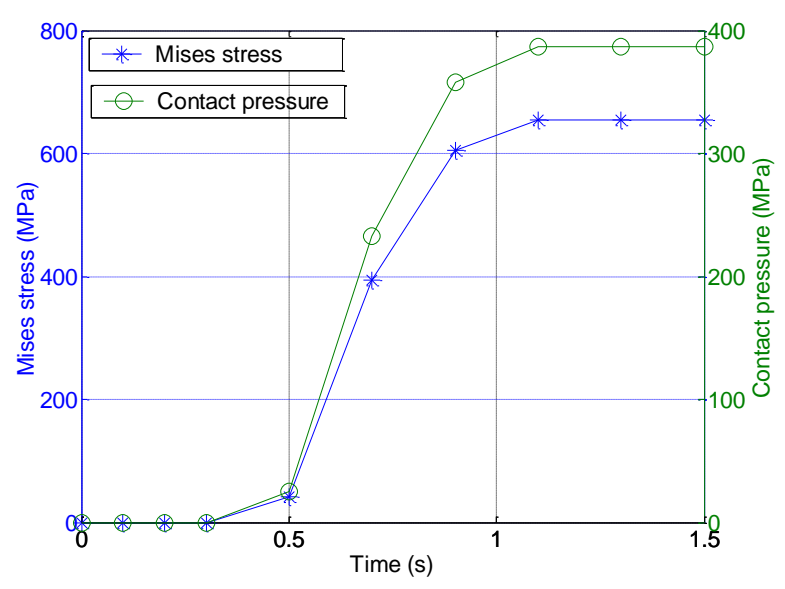

(b) Mises stress on the inside surface

Fig. 3 FEM simulation of the assembly

The traditional approach to determine the clamping torque of a shrink-fit is based on Lame's equation to predict radial pressures at the interface of the components and knowledge of the coefficient of friction and length of contact. In [11], a simpler method is introduced as follows. The clamping torque $T$ can be calculated by Eq. 1 .

$$
T=P \cdot A \cdot f \cdot R
$$

where, $P$ is the contact pressure on the clamping surface of the tool holder, $A$ is the contact area between the tool holder and the tool shank, $f$ is the friction coefficient, $R$ is the radius of the tool shank.

Given the typical friction coefficient $f=0.7$ and the dimension in Fig. 1 [12],

$$
T=0.35 P \cdot \pi \cdot d^{2} \cdot L_{1}
$$

The calculated contact pressure $P$ and the clamping torque is $386.915 \mathrm{MPa}$ and $34.46 \mathrm{Nm}$, respectively. In micro/nano milling, the cutting forces are smaller than several tens of Newton [13]. It shows that the clamping torque is large enough for the designed tool holder in case 1.

\section{Key factors analysis}

From Fig. 1, it seems that the hole size $d$ and the outside size $D$ of the tool holder affect the heating expansions and cooling shrinkage directly. Based on the above introduced FEM models, the two factors are analyzed. Then, the systematic design procedure is proposed.

In case 1 , the hole diameter is $10 \mu \mathrm{m}$, which is smaller than the nominal shank diameter. After heating to a temperature of $450^{\circ} \mathrm{C}$, the hole diameter is $11.884 \mu \mathrm{m}(2 \times 10.942-10)$, which is larger than the nominal shank diameter and is large enough for the smooth insert of the shank. In order to identify the effects of the designed hole sizes, other two simulations were conducted with the hole diameters of $15 \mu \mathrm{m}$ (case 2) and $20 \mu \mathrm{m}$ (case 3), respectively. Simulation results indicate the clearances for case 1 and case 2 are large enough for the smooth insert. For case 3 , the clearance is only $2.5 \mu \mathrm{m}$, which is too small to insert the tool shank into the tool holder. Therefore, it is better to determine the hole size and its tolerance between that of case 1 and case 2 . Furthermore, the stresses for case $2(1127 \mathrm{MPa})$ and case $3(1471 \mathrm{MPa})$ are both larger than the yielding stress ((1110 MPa)) of the tool holder material. Therefore, the hole size of case 1 is used for further analysis.

The outside size $D$ of the holder will obviously affect the stiffness, the heating and cooling efficiency, and the clamping force. Two other cases, namely case 4 and case 5 , with the outside diameters $D$ of $9 \mathrm{~mm}$ and $11 \mathrm{~mm}$ respectively are simulated (in case $1, D=7 \mathrm{~mm}$ ). Simulated results show that the outside diameter of the tool holder doesn't obviously affect the heated hole size and has limited effects on the inside hole expansions. The outside diameter of the tool holder is mainly 
determined by the requirements of stiffness and the corresponding geometric features on the workpiece to be cut.

Based on the above studies, a systematic design procedure is introduced. The primitive geometric design of the tool holder is conducted based on the requirements. The designed holder is modeled by FEM and evaluated by the stiffness analysis. After that, the heating FEM model is created to identify the clearance between the clamping hole of the tool holder and the tool shank. After the smooth insert of the tool shank into the tool holder is assured, the expansions are used to build the FEM cooling assembly model. The stress acting on the clamping surface of the tool holder must be smaller enough than the yielding stress of the tool holder material. After the above criteria are satisfied, the appropriate heating temperature can be determined for the designed specific holder. Finally, the novel shrink-fit tool holder is obtained.

\section{Evaluation}

The tool holder of case 1 is a typical small-sized one. Fig. 4 shows the designed tool holder in the clamping status and unclamping status. The end mill with a shank diameter of $3 \mathrm{~mm}$ can be inserted smoothly into the tool holder while the heating temperature reaches $430^{\circ} \mathrm{C}$, which is commensurate with the FEM analytical temperature. After several ten times heating and cooling, no cracks on the tool holder or obvious temperature variations for the smooth insert are found.
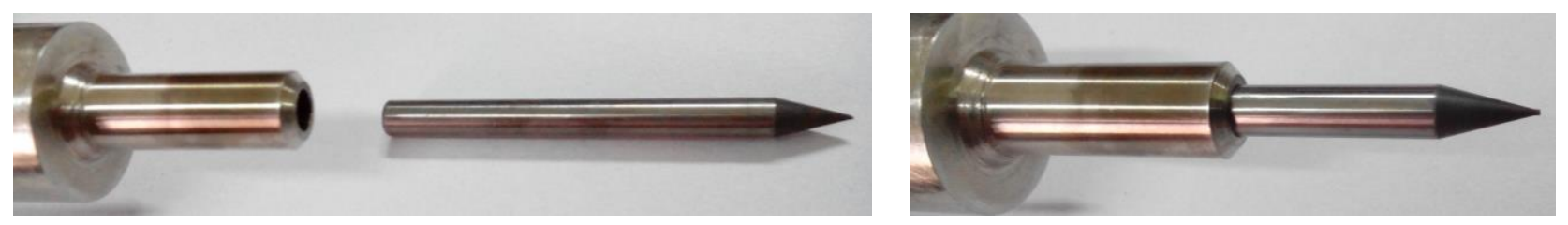

Fig.4 Clamping experiment for case 1

\section{Summary}

Heating and cooling models for the shrink-fit tool holder for micro/nano milling have been introduced based on FEM. The analysis shows that the clearance between the clamping hole and the tool shank, and the stresses exerting on the clamping surface of the tool holder are mainly affected by the clamping hole size, namely the interference between the tool holder and the tool shank. As long as the tool can be smoothly inserted into the tool holder and the stress on the clamping surface is lower than the yielding stress of the tool holder material, the clamping torque is always large enough for even heavy duty milling operations. Based on the study, a systematic design procedure for the shrink-fit tool holder has been proposed and evaluated.

\section{Acknowledgement}

The authors wish to express their appreciation for the financial support by the Natural Science Foundation of Shandong Province, China (ZR2011EEM010).

\section{References}

[1] H. M. Zhou, C.Y. Wang, Z.Y. Zhao, Dynamic characteristics of conjunction of lengthened shrink-fit holder and cutting tool in high-speed milling, J. Mater. Process Tech., 207(2008) 154162. 
[2] X. Cheng, K. Nakamoto, M. Sugai, S. Matsumoto, Z.G. Wang, K. Yamazaki, Development of ultra-precision machining system with unique wire EDM tool fabrication system for micro/nanomachining, CIRP Annals -Manuf. Tech. , 57(2008) 415-420.

[3] B.T. Simsek, E. Kuram, B. Ozcelik, The performance of different tool holders in dry milling, Int. J. Mach. Mach. Mater. 11(2011) 308-326.

[4] R.L. Norton, Machine design: an integrated approach, New Jersey: Prentice hall, 2000.

[5] C.E. Truman, J.D. Booker, Analysis of a shrink-fit failure on a gear hub/shaft assembly, Eng. Fail. Anal., 14(2007) 557-572.

[6] T. L. Schmitz, K. Powell, D.K. Won, G.S. Duncan, W.G. Sawyer, J.C. Ziegert, Shrink fit tool holder connection stiffness/damping modeling for frequency response prediction in milling, Int. J. Mach. Tool Manu., 47(2007) 1368-1380.

[7] Y. Zhang, B. McClain, D.D. Fang, Design of interference fits via finite element method, Int. J. Mech. Sci., 42(2000) 1835-1850.

[8] P. Pedersen, On shrink fit analysis and design, Computational Mechanics, 37(2006) 121-130.

[9] A. Sackfield, J.R. Barber, D.A. Hills, C.E. Truman, A shrink-fit shaft subject to torsion, Eur. J. Mech A-Solid, 21(2002) 73-84.

[10] A. Ozel, S. Temiz, M.D. Aydin, S. Sen, Stress analysis of shrink-fitted joints for various fit forms via finite element method, Mater. Design, 26(2005) 281-289.

[11] J.D. Booker, C.E. Truman, S. Witting, Z. Mohammed, A comparison of shrink-fit holding torque using probabilistic, micromechanical and experimental aproaches, P I Mech. Eng. B-J. Eng., 218(2004), 175-187.

[12] J. Abenojar, F. Velasco, J.M. Torralba, J.A. Bas, J.A. Calero, R. Marce, Reinforcing 316L stainless steel with intermetallic and carbide particles, Mater. Sci. Eng., A335(2002) 1-5

[13] M. Nalbant, Y. Yildiz, Effect of cryogenic cooling in milling process of AISI 304 stainless steel, Trans. Nonferrous Met. Soc. China, 21(2011) 72-79.

[14] Z. Wang, M. Soshi, K. Yamazaki, A comparative study on the spindle system equipped with synchronous and induction servo motors for heavy duty milling highly stable torque control, CIPR Annals - Manuf. Tech., 59(2012) 369-372. 